\title{
A filosofia sistêmica de Fritjof Capra: Um olhar ecológico para a Física e para o Ensino de Física ${ }^{+}$
}

\author{
Daniel Pigozzo ${ }^{1}$ \\ Nathan Willig Lima ${ }^{1}$ \\ Matheus Monteiro Nascimento ${ }^{1}$ \\ Universidade Federal do Rio Grande do Sul \\ Porto Alegre - RS
}

\section{Resumo}

Neste artigo, apresentamos a Filosofia Sistêmica de Fritjof Capra. A partir de sua obra é possível distinguir a existência de dois paradigmas (entendidos como molduras filosóficas) no desenvolvimento da ciência moderna: o paradigma mecanicista, inspirado pela Física Clássica, e o novo paradigma, articulado a partir da Física Moderna. Segundo Capra, os problemas complexos do mundo contemporâneo podem ser mais bem enfrentados pelo novo paradigma. Para abordar o tema, apresentamos uma discussão sobre a visão de Capra acerca da natureza da ciência, da Filosofia da Física Clássica e da Filosofia da Física Moderna e suas repercussões em diferentes contextos culturais. Por fim, propomos uma extrapolação do pensamento de Capra indicando possíveis implicações de seu trabalho para a Educação em Ciências, para o Ensino de Física e suas respectivas áreas de pesquisa.

Palavras-chave: Natureza da Ciência; Epistemologia; Filosofia Sistêmica; Fritjof Capra; Misticismo Quântico; Física Quântica; Mecânica Quântica; Física Moderna; Física Moderna e Contemporânea.

\footnotetext{
${ }^{+}$The systemic philosophy of Fritjof Capra: An ecological look at Physics and at Physics Teaching

* Recebido: abril de 2019. Aceito: setembro de 2019.

${ }^{1}$ E-mails: daniel.pigozzo@ufrgs.br; nathan.lima@ufrgs.br; matheus.monteiro@ufrgs.br
} 


\begin{abstract}
In this article, we present the Systemic Philosophy of Fritjof Capra. From his work it is possible to distinguish the existence of two paradigms (understood as philosophical frameworks) in the development of modern science: the mechanistic paradigm, inspired by Classical Physics, and the new paradigm, articulated from Modern Physics. According to Capra, the new paradigm deals better with the complex problems of the contemporary world. To introduce this subject, we present a discussion of Capra's view of the nature of science, of the Philosophy of Classical Physics and of the Philosophy of Modern Physics and its repercussions in different cultural contexts. Finally, we propose an extrapolation of Capra's thinking, indicating possible implications of his work for Science Education, Physics Teaching and their respective areas of research.
\end{abstract}

Keywords: Nature of Science; Epistemology; Systemic Philosophy, Fritjof Capra; Quantum Mysticism; Quantum Physics; Quantum Mechanics; Modern Physics; Modern and Contemporary Physics.

\title{
I. Introdução
}

A área de Educação em Ciências e, especialmente, de Ensino de Física tem se preocupado com a possibilidade de não apenas discutir conceitos científicos em sala de aula, mas de promover uma reflexão sobre como a própria ciência funciona e interage com diferentes esferas da cultura humana. Existem diferentes abordagens para lidar com tal preocupação. E, de forma geral, podemos apontar, apenas a título de exemplo, a inserção de elementos de História e Filosofia da Ciência (HFC), de Natureza da Ciência (NdC) e de discussões sobre as relações entre a Ciência, Tecnologia e Sociedade (CTS) no âmbito escolar, como tentativas de fornecer aos alunos um olhar mais profundo e complexo sobre como a ciência funciona e qual seu papel social.

Pode-se, ademais, apontar o texto seminal de Mathews (1988) como o precursor de uma "virada epistemológica2", privilegiando a adoção de HFC no âmbito educacional, a qual se tornou uma perspectiva crescente na área de pesquisa em ensino desde então (RUTHERFORD, 2001), juntamente com as discussões CTS (MELO; ALBUQUERQUE; CHRISPINO, 2017; PONTES; MELO; CHRISPINO, 2016; TOLEDO et al., 2016). Esses movimentos buscam promover uma concepção mais ampla do conhecimento científico e da

\footnotetext{
2 Epistemologia é a área da Filosofia dedicada a estudar a própria natureza do conhecimento. Muitas vezes, usase o termo Epistemologia da Ciência como sinônimo de Filosofia da Ciência. Por outro lado, o termo Natureza da Ciência (NdC) é utilizado para se falar de questões não somente epistemológicas, mas também políticas, sociológicas, psicológicas etc.
} 
prática científica em comparação com a visão de mundo oferecida pelo ensino bancário 3 (FREIRE, 2013) o qual, muitas vezes, pode ser associado a uma visão positivista (KINCHELOE; TOBIN, 2009) não somente no ensino de Física Clássica, mas também no ensino de Física Moderna e Contemporânea (JOHANSSON et al., 2018; LIMA et al., 2018; LIMA; OSTERMANN; CAVALCANTI, 2017).

Pode-se avaliar o panorama geral de produções acadêmicas sobre perspectivas que discutem NdC no campo educacional (incluindo as abordagens de HFC e CTS) no trabalho de Aikenhead (2003) que apresenta um vasto panorama sobre NdC e CTS na área de Educação em Ciências e o trabalho de Abd-El-Khalick e Lederman (2000), que apresenta uma revisão do impacto de diferentes estratégias na concepção de professores sobre a ciência. No caso do Ensino de Física propriamente, uma revisão de literatura internacional sobre HFC foi realizada por Teixeira, Greca e Freire (2012).

No contexto nacional da Pesquisa em Ensino de Física, o Caderno Brasileiro de Ensino de Física tem, historicamente, publicados artigos com foco em HFC, resguardando uma de suas linhas editoriais apenas para tal temática, e publicado artigos teóricos apresentando o pensamento de diferentes autores, filósofos e sociólogos, sobre HFC, NdC e CTS e suas implicações para o Ensino de Física. Em especial, pode-se destacar a existência de trabalhos sobre Popper (SILVEIRA, 1989, 2002), Lakatos (SILVEIRA, 1996), Bachelard (LOPES, 1996), Kuhn (OSTERMANN, 1996), Feyerabend (REGNER, 1996), Laudan (PESA; OSTERMANN, 2002), Fleck (DELIZOICOV et al., 2002) e Latour (LIMA; OSTERMANN; CAVALCANTI, 2018).

Uma das questões tratadas pela Epistemologia das Ciências refere-se ao "problema da demarcação". Discute-se, nesse sentido, se existem ou não critérios que possam claramente diferenciar ciência de não ciência e, caso existam, quais são eles. Pode-se pensar, por outro lado, que a mesma pergunta pode ser feita para a própria Epistemologia. Isto é, existem elementos claros que distingam a Epistemologia de outras áreas do conhecimento? O que caracteriza um certo autor como epistemólogo e outros não? Por que, em revistas especializadas, como o Caderno Brasileiro de Ensino de Física, fala-se de pensadores como Karl Popper, Imre Lakatos, e até mesmo Paul Feyerabend e Bruno Latour, mas, até então, não há nenhum trabalho sobre Fritjof Capra?

Fritjof Capra é um físico austríaco. Recebeu o título de doutor em Física teórica pela Universidade de Viena e dedicou 20 anos a pesquisas teóricas sobre Física de altas energias ${ }^{4}$. Em 1975, publicou seu livro O Tao da Física: Uma Exploração dos Paralelos entre a Física Moderna e o Misticismo Oriental (título original: The Tao of Physics: An Exploration of the Parallels Between Modern Physics and Eastern Mysticism) pelo qual ficou internacionalmen-

\footnotetext{
3 Freire (2013) indica que a origem do ensino bancário é uma ontologia bancária. Pelo entendimento de que a prática docente é sustentada por visões epistemológicas e ontológicas, um professor não terá uma prática bancária se verdadeiramente adotar uma concepção mais contemporânea de conhecimento.

${ }^{4}$ Informações disponíveis em: <https://www.fritjofcapra.net/about/>. Acesso em: 9 set. 2019.
} 
te famoso. Desde então, dedica-se a discutir sobre ciência, ecologia e sistemas complexos. Embora Capra tenha se proposto, e ainda se proponha, a pensar sobre a Natureza da Ciência, usualmente não se vê a adoção de sua proposta como referencial teórico, exceto em raras exceções, como o trabalho de Harrison (1979). Conforme Capra admite em uma entrevista ${ }^{5}$, suas obras, embora populares, não entraram nas Universidades. Os Estudos (sociológicos) das Ciências têm reiteradamente mostrado que os critérios de demarcação científica estão sempre atrelados a questões políticas (SHAPIN; SCHAFFER, 1985) e culturais (DASTON; GALISON, 2007) e não podem ser verdadeiramente compreendidos, a menos que se leve em conta as disputas de poder (FOUCAULT, 2018). Da mesma forma, a apresentação de uma Epistemologia da Ciência, enquanto uma disciplina ou área do conhecimento, também envolve disputas e conflitos que servem, em última instância, a um determinado regime de verdade e, por consequência, a um determinado regime de poder (FOUCAULT, 2018).

Assim, se Fritjof Capra, até hoje, nunca foi reconhecido como um filósofo da ciência, isto pouco diz sobre a qualidade de seu trabalho, mas, tão somente, sobre o quanto ele rompe com o paradigma hegemônico e com a estrutura de poder que ele estabelece. Poderia se contra-argumentar que outros autores que desafiam a hegemonia epistêmica da ciência (como Feyerabend e Latour) são reconhecidos pelo meio acadêmico. Apontamos, entretanto, que a análise de Capra, em alguns sentidos, é muito mais radical do que a de alguns epistemólogos frequentemente associados ao relativismo. Primeiramente, ele se arrisca a ultrapassar as linhas demarcatórias da filosofia e da teologia ocidental, buscando paralelos entre a ciência moderna e tradições filosóficas orientais. Fazendo uma descrição sociológica, Fritjof Capra rompe com o que Boaventura de Sousa Santos chama de linhas abissais (SANTOS; MENESES, 2009)6.

Em segundo lugar, Capra descreve a natureza da ciência como sendo coadunada com visões extrativistas do mundo, como o patriarcado, o colonialismo e o capitalismo, desafiando explicitamente não só a estrutura da ciência, mas a estrutura da sociedade ocidental em seus livros O Ponto de Mutação (publicado pela primeira vez em 1982) e A Teia da Vida (publicado pela primeira vez em 1996).

Em especial, cabe-se ressaltar que, conforme descreve Feyerabend (2011), a ciência moderna foi, em parte, desenvolvida em oposição às instituições religiosas europeias da Idade Média e Moderna. Fazer ciência no período de Galileu, em certo sentido, significava exercer um grande ato de resistência e irreverência frente à estrutura de poder vigente. Conquanto isso, o estabelecimento da ciência enquanto estrutura hegemônica fez com que o pensamento mítico e religioso - antes hegemônico - passasse a ser alvo de rejeição: a vitória da liberdade

\footnotetext{
${ }^{5}$ A entrevista pode ser encontrada em <https://www.youtube.com/watch?v=ta3fHs9NRoo>. Acesso em: 8 agos. 2019.

6 Ao longo do desenvolvimento da Metrópole, a ciência disputou e disputa com a Filosofia e a Teologia os métodos de obtenção de verdade. Muitos pensadores contra hegemônicos (como Latour e Feyerabend) diluíram o poder da ciência, fortalecendo as outras duas formas de conhecimento metropolitanas. Fritjof Capra fugiu dessa perspectiva eurocentrista (em 1975) e apresentou a Física Moderna como compatível com a moldura filosófica de tradições místicas não europeias no livro O Tao da Física.
} 
científica em um primeiro momento viabilizou a deslegitimação de outras formas de cultura e conhecimento (FEYERABEND, 2011), o que é uma das manifestações do que Boaventura denomina "epistemicídio" (SANTOS; MENESES, 2009). "Deus" foi expulso de toda descrição da realidade (LATOUR, 2013) e, dessa forma, as filosofias místicas ganharam um status vulgar e marginal e as tradições místicas de povos não europeus ainda mais.

Em O Tao da Física, portanto, Capra (2011) rompeu com o silêncio secular da Física, propondo que a moldura filosófica da Física Moderna pode encontrar paralelos no misticismo oriental. Isso não significa dizer que a Física Quântica prova a existência de Deus, da alma ou da reencarnação. Tampouco implica que, ao invés de estudar equações diferenciais, físicos deveriam meditar mais. Capra somente propõe a ideia de que há caminhos para diálogos entre as implicações filosóficas da Física Moderna e a metafísica oriental.

Tal reconhecimento vai ao encontro de diversos estudos historiográficos que têm reiterado a existência de intensos e complexos diálogos entre ciência e espiritualidade. Barbour (1990), por exemplo, propõe quatro tipos gerais de interação entre as duas áreas a partir de dois eixos compatibilidade-incompatibilidade e similar-diferente. Quando são incompatíveis e diferentes, elas se relacionam por conflito. Quando são incompatíveis e similares, elas dialogam. Quando são compatíveis e diferentes, elas são independentes; e quando são compatíveis e semelhantes, elas podem ser integradas. Tal esquema pode ser encontrado em estudos historiográficos como o trabalho de Helge Kragh (2004) sobre a Cosmologia. Pode-se mencionar, também, nessa temática, a análise de Max Jammer (2000) sobre Albert Einstein e a espiritualidade. No trabalho de Bagdonas e Silva (2015), discussões sobre as relações entre religião e ciência em aulas de Física foram identificadas como uma maneira eficiente de estimular reflexões sobre NdC. Dessa forma, os paralelos estabelecidos por Capra, embora possam gerar mal-estar à vertente hegemônica da comunidade da Física e do Ensino de Física, dialoga com perspectivas importantes da História e Filosofia contemporâneas.

Em especial, deve-se ressaltar que chama-se de misticismo quântico correntes que interpretam a Física Quântica a partir de um viés idealista ou mesmo espiritualista (FREIRE JR; PESSOA JR; BROMBERG, 2011; MUSSATO, 2018), e alguns autores classificam Capra como um de seus percursores (MOURA; SANTOS, 2017; SAITO, 2018). Nós, entretanto, entendemos que Capra não adere explicitamente aos pressupostos do misticismo quântico, embora o estabelecimento dos paralelos possa ter motivado interpretações subsequentes. Amit Goswami (2006), líder do movimento de ativismo quântico, reconhece que leu Capra, mas que seus paralelos não iam longe o suficiente? .

Mário Schenberg, físico teórico brasileiro de grande prestígio, ex-presidente da Sociedade Brasileira de Física e ex-diretor do Departamento de Física da Universidade de São Paulo, assinou o prefácio da edição brasileira do livro O Tao da Física, em que escreve:

\footnotetext{
${ }^{7}$ Para uma história cultural sobre Fritjof Capra, recomendamos a consulta ao trabalho de Rocha (2015).
} 
O Tao da Física, de Fritjof Capra, é indiscutivelmente um dos livros mais fascinantes das últimas décadas. Sua leitura é necessária aos físicos e estudiosos da Filosofia da Ciência, como a todas as pessoas interessadas em Filosofia da Natureza e da Ciência. (...) A leitura e o estudo de O Tao da Física será de grande utilidade para os estudantes de Física, que encontrarão nesta obra sínteses notáveis de algumas questões fundamentais da teoria da relatividade, da mecânica quântica, da teoria quântica de campos e da cosmologia relativista. Poderão também encontrar nela uma introdução às ideias de não-separatividade, que adquiriram tanta importância na teoria quântica atual, desde as discussões suscitadas pelo famoso teorema de Bell.

Em síntese, um dos méritos de Capra é o de reconhecer a existência de uma "moldura filosófica", chamada por ele de paradigma mecanicista, inspirado na Física Clássica, a qual é responsável pela crise observada na sociedade contemporânea, o que alguns autores chamam de Crise do Antropoceno (crise ambiental, social, política etc.) (FOSTER, 2016). Em contrapartida, o autor reconhece que a Física Moderna enseja uma nova moldura filosófica, ecológica, capaz de apresentar novas soluções para estes problemas complexos, seja na Física, na Economia, na Saúde ou na Psicologia. Com isso, o primeiro objetivo deste trabalho é resgatar o pensamento sistêmico de Fritjof Capra, ressaltando as características dos dois paradigmas segundo o autor. Para tanto, introduzimos conceitos e discussões realizadas por Capra nos livros O Tao da Física (2011), O Ponto de Mutação (2012a) e A Teia da Vida (2012b).

O segundo objetivo consiste em dar um passo no sentido de extrapolar a descrição de Capra, ressaltando as implicações do paradigma mecanicista e do "novo paradigma" para os campos da Educação em Ciências e Ensino de Física e das pesquisas em Educação em Ciências e Ensino de Física. Para tanto, a trajetória a ser seguida é a seguinte: na seção 2, discutimos a visão sobre natureza da ciência de Capra; na seção 3, apresentamos a Filosofia da Física Clássica e como ela impactou diferentes áreas da cultura; na seção 4, apresentamos a Filosofia da Física Moderna e como ela pode impactar nossa sociedade. No fim, na seção 5, apresentamos implicações do pensamento de Capra para o Ensino de Física e para a Pesquisa em Ensino de Física.

\section{Descrição da Ciência e da Prática Científica}

Em diferentes trechos de O Tao da Física (1989), Capra destaca que as ciências naturais, especialmente a Física, se constituem por um embasamento atitudinal empírico e um pensamento analítico e racional. Contudo, o autor não as coloca como objetivas e livres de valores. Dessa forma, pode-se perceber que o autor não pode ser classificado como um pensador relativista ${ }^{8}$, uma vez que enfatiza a associação do pensamento analítico racional com a

\footnotetext{
${ }^{8}$ Chamamos de relativista às tradições filosóficas que consideram o conhecimento científico equipolente a qualquer outro conhecimento. Pode-se mencionar Feyerabend $(1995,2010,2011)$ como um pensador comumente associado a tal perspectiva, por enfatizar atos de contra-indução como os promotores do desenvolvimento cientí-
} 
prática empírica como modus operandis das ciências - como fazem epistemólogos como Bachelard (2009). Por outro lado, ele reconhece a existência de fatores valorativos e, portanto, subjetivos na construção científica, o que faz o conhecimento desenvolvido ser, sempre, dependente do contexto social. Capra destaca a existência de uma ligação intrínseca entre os padrões observados na natureza pelos cientistas e os padrões de suas mentes, estes relacionados à consciência e a valores pessoais - o que lembra uma espécie de kantismo. Ademais, Capra (2006a) vale-se em suas obras do termo "paradigma" - o que explicita a influência de Thomas Kuhn (1996) sobre seu pensamento.

Há, também, em seu argumento, um reconhecimento de que, em grande parte do trabalho científico, essa dependência de padrões mentais e sistemas de valores não é sempre explícita. Elas se tornam evidentes a partir da análise das estruturas mais abrangentes, como os sistemas de pesquisa nas quais estão inseridas. Nesse sentido, quando trata do aspecto racional do conhecimento científico, o autor não se posiciona acriticamente ao descrever as estruturas sequenciais e lineares de caráter simbólico, abstrato e conceitual desse conhecimento. De fato, muito da sua reflexão envolve enfatizar o reducionismo das investigações intelectuais.

No início da discussão sobre mudança de paradigma e das descrições sobre o trabalho científico em O Tao da Física, o autor afirma:

\begin{abstract}
É interessante seguir a evolução da ciência ocidental ao longo do seu caminho em espiral, desde as filosofias místicas do dealbar grego, progredindo e cimentando um impressivo desenvolvimento do pensamento intelectual, sucessivamente desligado das suas origens místicas para desenvolver uma visão do mundo em nítido contraste com a do Extremo Oriente. Nos seus mais recentes desenvolvimentos a ciência ocidental ultrapassou finalmente esta visão, e retomou os antigos gregos e a filosofia oriental. Este retomo não é, no entanto, intuitivo, mas baseado em experiências sofisticadas e de grande precisão, e num rigoroso e consistente formalismo matemático (CAPRA, 1989, p. 23).
\end{abstract}

Ainda nesse sentido, sua descrição de ciência também inclui um "método científico de abstração" (CAPRA, 1989) o qual é caracterizado como eficiente, mas de modo algum ilimitado e onipotente, sendo sua eficiência relacionada ao formalismo matemático e suas limitações relacionadas a uma intrínseca falta de precisão nos modos de expressão cotidianos. Tais relações, como discutimos, são importantes para a construção de alguns dos paralelos entre Física Quântica e aspectos místicos de filosofias orientais.

As limitações do pensamento conceitual no trabalho de descrição da realidade, segundo Capra, estão impressas no método científico de abstração, o que o faz igualmente incapaz de descrever integralmente essa realidade. A pesquisa científica, reflexo de tal método científico de abstração, seria constituída de três partes essenciais: análise empírica de um

fico e por defender que qualquer metodologia possui limites, não havendo uma racionalidade suficientemente abrangente e universal. 
evento, esquematização de informações experimentais sob o formalismo matemático e, por último, verificação e interpretação das predições dos resultados experimentais e das implicações iniciais. Tais etapas não ocorrem de modo categórico e sequencial, mas o papel da experiência sensível é sempre essencial e preceptor à pesquisa. Nesse sentido, observa-se que Capra não acrescenta nenhuma grande ruptura com os esquemas clássicos de descrição da ciência.

No desenvolvimento do produto textual das duas últimas etapas, aquilo que chamamos de teorias ou modelos, as limitações nos modos de expressão cotidianos voltam a ter importância. Para enfrentar tais limites, torna-se necessária a construção de modelos mais abrangentes de comunicação que melhor se adaptem a critérios de compreensão estabelecidos na última etapa, a de verificação e interpretação das predições dos resultados experimentais e das implicações iniciais. Tratando de forma cada vez mais preciosista os códigos e conceitos dos nossos sistemas intelectuais, dando-lhes uma forma mais arrojada, fazemos mais interligações rigorosas e distanciamo-nos do mundo concreto. Para representar esse distanciamento, o autor se refere frequentemente ao lema "o mapa não é o território" de Alfred Korzybski. A partir deste lema, Capra desenvolve uma comparação na qual o "mapa" representa os modelos, códigos e símbolos consistentes do formalismo matemático, mas que são sempre apenas representações aproximadas do "território" que é ao que de fato atribuímos caráter de materialidade.

De todas as características da Natureza da Ciência ressaltadas por Capra, entendemos que o conceito de "paradigma", tomado da filosofia de Kuhn, foi de grande importância para o desenvolvimento de sua obra, sendo definido como o conjunto de valores, concepções e técnicas compartilhadas pela comunidade científica para determinar e resolver os problemas legítimos (CAPRA, 2012b). Nesse sentido, quando olhamos a ciência, podemos reconhecer nela uma moldura, ou estrutura, filosófica (CAPRA, 1989) ou o que alguns autores poderiam chamar de cosmovisão (BUNGE, 2016).

Nesse sentido, o ponto central da proposta de Fritjof Capra é mostrar que a moldura filosófica da Física Clássica, chamada de paradigma mecanicista, embora tenha subsidiado o desenvolvimento de diversas ciências e de diversas áreas culturais, não é mais suficiente para lidar com as questões da sociedade contemporânea como, por exemplo, de que maneira podemos integrar conhecimentos físicos, biológicos, químicos, cognitivos e sociais para ajudar a construir comunidades sustentáveis. Por outro lado, a moldura filosófica que surgiu com o desenvolvimento da Física Moderna, o que Capra chama de paradigma ecológico, apresentase como um caminho necessário e potente para lidar com as dificuldades do mundo no século XXI. Nas próximas seções, apresentaremos os dois paradigmas da visão de Capra, bem como suas implicações para a nossa sociedade. 


\section{Filosofia da Física Clássica}

O desenvolvimento da Física Clássica é, usualmente, associado aos trabalhos de vários indivíduos entre os séculos XVI e XVII, dos quais destacamos Galileu Galilei (1914), segundo o qual a ciência seria capaz de desvendar, ou descobrir, as verdades (ou essências) do mundo - o que pode ser classificado como uma visão essencialista (POPPER, 1963). Além de Galileu, os trabalhos de Descartes (2001) e Bacon (1984) tiveram grande impacto na descrição da ciência moderna (AMÉRICO, 2001). Enquanto a proposta de Bacon ressalta a importância da empiria e da experimentação, o trabalho de Descartes enfatiza a razão como fonte de saber, subsidiando as duas grandes vertentes do pensamento moderno: o empirismo e o racionalismo.

Capra (2006a, 2006b) ressalta especialmente que a classificação de Descartes dos entes do mundo em res cogitans e res extensa implicou o desenvolvimento da percepção da natureza como algo inerte, desprovido de vida e que, portanto, era completamente passível de ser explorado. Tal descrição sobre a gênese da ciência moderna está alinhada com o pensamento de outros autores pós-modernistas (ou, pelo menos, não modernistas) (LATOUR, 1999; SANTOS, 2008). Ademais, a visão de Universo como um grande relógio proposta por Descartes enfatizava a ideia de um mundo determinista no qual as leis, uma vez descobertas, seriam capazes de descrever passado, presente e futuro, como também propôs Laplace posteriormente.

Embora tenha sido Descartes uma das primeiras personagens de destaque a tratar dessa visão de mundo mecanicista, Newton foi capaz de contribuir fortemente com o arcabouço teórico para fazer o Grande Relógio do Universo começar a girar (CAPRA, 2012a). O desenvolvimento dessa visão tirou da Física, em grande parte, o interesse pela questão da vida, da consciência e de aspectos subjetivos, uma vez que a res extensa deveria ser desprovida de todas essas qualidades.

Aos olhos dos físicos da Idade Moderna, as concepções supracitadas transformaram a realidade em um intricado sistema mecânico. Nas palavras do autor, "[A] divisão «cartesiana» permitiu aos cientistas tratar a matéria como morta, e completamente separada de si próprios" (CAPRA, 1989, p. 25). Pode-se entender a partir da narrativa de Capra (2006) que essa visão da natureza como algo inerte é um dos fatores que viabilizou a vontade humana de explorá-la como um conjunto de objetos isolados. Tal visão de relação entre visão de mundo e atividade de exploração também é defendida por Santos e Meneses (2009), Latour (2013) e Arendt (2007). Nesse sentido, Capra, baseado nas discussões ecofeministas (MIES; SHIVA, 2014), ressalta que a ciência é mais um braço do patriarcado. Dessa forma, o desenvolvimento científico-tecnológico é apenas uma outra dimensão do machismo e do racismo estruturantes. $\mathrm{Na}$ área de Educação em Ciências, pode-se encontrar ideias semelhantes nos trabalhos de John Lemke (2011) que aponta o caráter machista e conservador da ciência.

Ademais, um elemento essencial da visão cartesiana que se sustenta até o presente é o método reducionista (ou atomista). Isto é, para resolver um problema complexo, deve-se 
reduzi-lo em pequenos problemas passíveis de serem resolvidos. Ao resolver cada situação individualmente, estaria se progredindo no sentido de resolver o problema maior. É dessa forma, que fenômenos complexos, como a sociedade, são reduzidos a fenômenos biológicos, que são reduzidos a fenômenos químicos, que são reduzidos a fenômenos físicos, que são reduzidos a equações matemáticas.

Para Capra, os primeiros passos em direção a uma ruptura com a Física newtoniana são dados por Faraday e Maxwell na substituição do conceito de força, elemento-chave da descrição objetiva de Newton, pelo conceito de campo, uma quantidade ainda mais enraizada na metafísica, possuindo seu próprio nível de realidade "sem qualquer referência aos corpos materiais" (CAPRA, 1989)9.

Essa primeira tentativa de ultrapassar os limites do pensamento físico de Newton são comedidos, de tal forma que mesmo Maxwell ainda buscava uma interpretação mecanicista dos resultados de seu trabalho (CAPRA, 1989, p. 54). No final do século XIX, porém, as implicações da eletrodinâmica de Maxwell já competiam com o protagonismo da visão newtoniana, demonstrando um desequilíbrio na tentativa de se construir uma visão única, integral e objetiva do mundo.

\section{III.1 Implicações da Física Clássica para outras áreas da Cultura}

Devido aos vários sucessos advindos da visão cartesiana, a cosmovisão mecanicista não ficou circunscrita à descrição do movimento de partículas clássicas na Física newtoniana. Ela passou, segundo Capra (1989), a ser o paradigma hegemônico de toda sociedade ocidental moderna. Tudo, absolutamente tudo no Universo, tornou-se passível de ser estudado como uma peça morta em um sistema mecânico como um relógio. Em especial, em O Ponto de Mutação, Capra (2006b) ressalta quatro áreas influenciadas pela visão mecanicista: a concepção de vida, a concepção de saúde e cura, a psicologia e a economia ${ }^{10}$.

Embora a definição de vida seja discutida em O Ponto de Mutação (2012a), em A Teia da Vida (CAPRA, 2012b), Capra se dedica unicamente a esse tema. Nesse livro, o autor ressalta a descrição mecanicista do sistema sanguíneo feita por William Harvey em 1628 a qual motivou a escrita de tratados como O Homem uma Máquina de Julien de La Mettrie em 1748.

O desenvolvimento da química, entretanto, conduziu a uma complexificação da concepção do ser humano, sem deixar, entretanto, de lado o pensamento mecanicista. Conforme já comentamos, tal visão é traduzida na concepção reducionista de que os fenômenos biológicos podem ser reduzidos às leis da química, e essas às leis da Física. Desde o século XIX, o determinismo newtoniano passou a ser traduzido no determinismo genético, reforçando que a

\footnotetext{
${ }^{9}$ Para uma discussão sobre a importância do conceito de campo no desenvolvimento da Física, sugerimos o trabalho de Albert Einstein (2006).

$10 \mathrm{O}$ detalhamento da influência do paradigma newtoniano em outras áreas é feito em O Ponto de Mutação por mais de 250 páginas. Nessa seção, temos a intenção de apenas traçar as linhas gerais da análise de Capra.
} 
concepção de mundo mecanicista não foi abandonada, mas apenas adaptadas às novas descobertas da biologia.

A concepção de cura e tratamento do pensamento mecanicista é uma consequência direta de sua concepção de vida (CAPRA, 2012a). Se o organismo vivo é uma máquina, cabe ao médico reconhecer a peça defeituosa para consertá-la. Tal visão de saúde, chamada por Capra de modelo biomédico, conduziu a superespecialização da medicina, dentro de uma concepção reducionista de saúde, ignorando, muitas vezes, as relações sistêmicas do corpo e as relações do próprio corpo com o seu ambiente. Tal visão, ademais, excluiu qualquer "significado" existencial que poderia ser atribuído à doença e à morte, preocupando-se apenas com questões técnicas. $\mathrm{O}$ modelo biomédico também não leva em consideração questões emocionais, espirituais e de bem-estar do paciente. Capra não quer com isso desprezar ou menosprezar a medicina científica. Pelo contrário, percebendo seu valor e muitos sucessos, reconhece suas limitações e a necessidade de complementação com uma visão holística.

A psicologia, também, no paradigma mecanicista, adota uma visão não ecológica, isto é, sem analisar a relação do sujeito com o ambiente e com outros seres, descrevendo as características da mente (enquanto um ente intrínseco) no caso da psicanálise de Freud ou do comportamento no caso de behaviorismo. A proposição de uma psicologia científica, pautada na noção de ciência herdada da Física newtoniana, também promoveu uma negação da espiritualidade como dimensão intrinsecamente humana e de qualquer fenômeno relacionado à consciência e a seus estados alterados (CAPRA, 2012a).

Por fim, a visão mecanicista foi traduzida na economia como a noção de que seria possível promover uma ciência econômica livre de valores e crenças subjetivas, assim como a mecânica newtoniana alega ser (CAPRA, 2012a). Os economistas, de uma forma geral, tendem a negar a base axiológica de seus trabalhos, afirmando promover uma ciência neutra e objetiva. Dentro desse contexto, o modelo de desenvolvimento econômico capitalista encontra dificuldades em acabar com contradições quando confrontado por questões ecológicas. Essa lógica de exploração também herda a noção de natureza inerte que poderia ser explorada sem nenhuma consequência social ou moral.

\section{Filosofia da Física Moderna}

Antes de tratar extensamente da moldura filosófica da Física Moderna em O Tao da Física, Capra (2011) lida com a contextualização de eventos do início do século XX, começando pelo trabalho de Albert Einstein e os revisionismos aos quais são submetidos os conceitos de espaço e tempo absolutos, além das novas perspectivas sobre a realidade, estrutura e organização dos átomos e da matéria.

$\mathrm{O}$ autor destaca os esforços intelectuais daqueles que "ultrapassaram os limites da Física newtoniana" de maneira veemente, reconstruindo as origens da Física Moderna a partir dos dois artigos de 1905 escritos por Einstein (1905a, 1905b). Consequentemente, são destacadas a teoria da relatividade e a nova concepção sobre radiação eletromagnética como esfor- 
ços científicos extremamente relevantes e também como "monumentos intelectuais imponentes - as pirâmides da civilização moderna" (CAPRA, 1989, p. 55). Nesse sentido, é evidente que a busca de Einstein por uma Física unificada e harmoniosa também participam da narrativa de Capra sobre o século XX.

A partir disso, seguem-se as investigações sobre as estruturas dos átomos encabeçadas por Rutherford e Bohr. Ambos foram responsáveis por atualizar as escalas e a organização do átomo, atribuindo a ele não mais aquela qualidade de ponto sólido e indestrutível, mas de um corpo microscópico formado por um núcleo muito pequeno, como já propunha Thomson, e amplas regiões de espaço contornadas por partículas ainda menores, os elétrons. Tais estudos foram acompanhados dos trabalhos de de Broglie, Schrödinger, Pauli, Heisenberg e Dirac em algo que Capra descreve como um levantamento conjunto de esforços que atravessou diversas fronteiras nacionais e levou ao encontro da formulação matemática adequada para a Física Quântica.

Nessas investigações, a comunidade científica foi confrontada com aspectos dualísticos e abstratos das entidades subatômicas e das radiações eletromagnéticas cujo efeito sobre a imaginação dos físicos foi destruidor (CAPRA, 1989). Para tratar profundamente sobre esses efeitos, Capra retorna, em seu argumento, ao início do século XX e destaca o trabalho de Planck e seu quantum de ação o qual, poucos anos à frente, foi expandido e apresentado por Einstein como algo mais próximo de um aspecto fundamental da natureza. As contradições aparentes no comportamento da luz e das demais formas de radiação eletromagnética causaram revisionismos nas concepções mecanicistas sobre a realidade da matéria e culminaram na visão quântica, que descreve as menores partes do nosso mundo em termos de padrões de probabilidade.

Aproximando-se da segunda metade do século XX e do fim da contextualização, Capra apresenta os trabalhos científicos envolvendo a identificação de novas e diversas partículas que são capazes de alterar quaisquer concepções ingênuas de um físico sobre a existência de unidades elementares de matéria no nosso Universo. Afinal, na época da publicação da segunda edição de O Tao da Física, em 1983, mais de duzentas partículas eram conhecidas.

Apesar de admitir uma persistência em uma ampla busca por "blocos de construção básicos" na identificação da diversidade de partículas subatômicas, Capra reconhece que tais esforços pavimentaram a generalização do senso de que os adjetivos "elementar" e "fundamental" já não constituem uma tradução adequada a conceitos dos modelos quânticorelativísticos.

O tratamento que Capra dá à contextualização da Física Moderna flui de maneira coerente com a narrativa dos livros didáticos da área (LIMA et al., 2017, 2018, 2019; LIMA; OSTERMANN; CAVALCANTI, 2017). Alguns conflitos entre programas de pesquisa são praticamente omitidos (como a divergência do trabalho de Schrödinger frente as primeiras concepções da nova Física Atômica do século XX) em contraponto com algumas discussões 
que são realçadas (como as argumentações presentes nos textos de Bohr, Heisenberg e Einstein) e delineiam o argumento construído.

Ao falar da Física Moderna, e principalmente da Física Quântica, o autor descreve um saber demasiadamente abstrato, probabilístico e interconectivo. $\mathrm{O}$ estudo de pontos em comum entre Física Quântica e aspectos místicos das filosofias orientais é construído não para unir a comunidade física em um grande cerimonial de meditação e paz transcendental, mas sim para ajudar a compreensão de abstrações advindas do formalismo da Física Quântica e para expor a natureza aos nossos métodos de investigação de uma maneira inovadora e, possivelmente, mais adequada. Nesse sentido, Capra reforça que a união entre Física Moderna e misticismo oriental se dá no nível da moldura filosófica - isto é - em sua cosmovisão relacional e processual, em oposição ao reducionismo e objetivismo cartesianos.

A criteriosidade dos paralelos é destacável principalmente nos contraexemplos em que Capra (1989) demonstra não tomar qualquer comparação como construtiva ou verdadeira apenas pela possibilidade de ser feita. Além disso, o autor afirma que reconhecer paralelos entre a ciência ocidental e o misticismo oriental não significa aceitar que a ciência está apenas redescobrindo conhecimentos milenares que já foram formalizados por sábios orientais, nem que seria necessário aos físicos deixarem de lado as metodologias de suas pesquisas para começar a meditar ou aceitar que exista uma influência mútua, ou uma síntese, entre a ciência e o misticismo (CAPRA, 1989). Assim, ressaltamos que os paralelos não significam que os místicos chegaram às conclusões científicas, mas tão somente que sua cosmovisão é compatível com as descobertas da Física Moderna.

A primeira concepção mística alinhada às descobertas da Física Moderna é a noção de que todos os fenômenos são manifestações de uma realidade única e fundamental. À semelhança de Einstein, que buscava uma teoria de campo unificado, os místicos orientais consideram uma entidade subjacente como a única realidade: todas as suas manifestações fenomênicas são vistas como transitórias e ilusórias. Deve-se notar que, assim como no caso dos pensadores orientais, a busca de Einstein por tal concepção também é reconhecida como tendo origens metafísicas - a dizer - sua noção de Deus (JAMMER, 2000). "Esta realidade do misticismo oriental não pode ser identificada com o conceito de campo quântico da física porque essa realidade é tida como a essência de todos os fenómenos neste mundo e, consequentemente, está para além de todos os conceitos e ideias. O campo quântico, por outro lado, é um conceito bem definido que vem dar conta de alguns fenómenos físicos." (CAPRA, 1989, p. 125, grifo no original).

Ainda com relação a essa unidade, Capra comenta sobre o problema da medição na Física Quântica. Diferentemente da Física Clássica na qual, usualmente, é possível prever e determinar o efeito da medida no sistema observado (apesar de eventualmente ainda lidar com probabilidades), na Física Quântica, a medida desempenha um papel muito mais essencial, pois determina a projeção do sistema sobre um determinado autoestado (PESSOA JR., 2003). Não só isso, mas o próprio arranjo experimental, conforme montado pelo cientista, determina 
as propriedades do sistema a ser analisado. Dessa forma, pode-se interpretar que o observador possui alguma influência sobre as propriedades do sistema quântico. Embora algumas interpretações da Física Quântica tenham sugerido a noção de que é a consciência que é responsável pelo colapso da função de onda (GOSWAMI, 1990), Fritjof Capra não se compromete com tal tipo de interpretação no livro O Tao da Física. A visão de Capra, nesse sentido, é próxima a que Niels Bohr apresenta em diálogos com Heisenberg (1972).

A segunda concepção mística que se alinha com descobertas da Física Moderna, que, de certa forma, é consequência da visão de Unidade, é a ideia de que propriedades opostas são complementares. Capra traz o Taoísmo e sua concepção de equilíbrio de yin-yang para discutir essa perspectiva filosófica. De acordo com o Taoísmo, a natureza deve buscar um equilíbrio entre essas duas "forças" e, na verdade, cada uma delas possui dentro de si a semente do seu oposto - é isso que é representado no símbolo do yin-yang com um ponto de cor oposta em cada parte da figura. Capra comenta: "Energia e matéria, ondas e partículas, movimento e repouso, existência e não existência - estes são alguns dos conceitos opostos, ou contraditórios, que são transcendidos na física moderna" (CAPRA, 1989, p. 129). Deve-se lembrar que tal relação entre Física Moderna e Taoísmo não é invenção de Capra, mas era a percepção do próprio Niels Bohr. Mostramos, na Fig. 1, o brasão de Bohr, no qual o símbolo taoísta é mostrado e aparece em latim o ditado: "Os opostos são complementares". Com isso, ressaltamos que a noção de Complementaridade como um princípio filosófico mais amplo fora explorada pelo próprio Bohr.

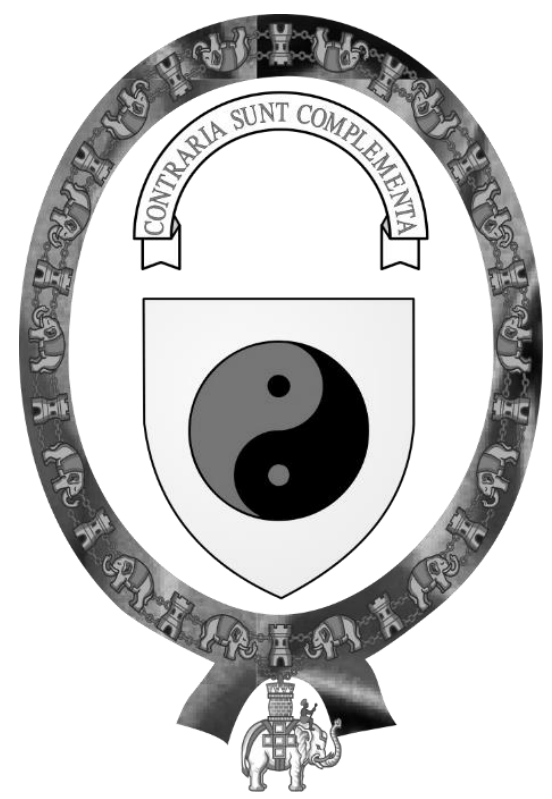

Fig. 1 - Brasão de Niels Bohr. Imagem adaptada de <http://commons.wikimedia.org/wiki/File:Coat_of_Arms_of_Niels_Bohr.svg>.

Além dessa cosmovisão unificante, a filosofia mística oriental ainda apresenta a noção de que a realidade que experienciamos não é sólida, mas vazia. Para o Budismo, por 
exemplo, a realidade que experienciamos no período de vigília é muito similar à experienciada no sonho - em ambos os casos é a mente que está projetando aquilo que percebemos. Para Buda, a essência última da realidade é o vazio de qualquer existência inerente. Embora essa não seja a visão da Física Moderna, pode-se entender que para um místico oriental seria muito mais fácil aceitar a visão atomista contemporânea do que para um cartesiano moderno, que acreditava na noção de substância material.

Ainda, na visão oriental, o universo nunca é composto por elementos estáticos - tudo, absolutamente tudo, está em constante mutação. Isso é representado pela noção de Dança de Shiva - o deus da destruição. Na filosofia oriental, assim, a destruição e a morte não são vistas como algo negativo - mas como parte do processo de existência da própria realidade. Mais uma vez, para um adepto dessa visão de mundo, é muito mais fácil aceitar que, no nível quântico, as partículas não estão imóveis em um corpo sólido, estão a todo tempo interagindo, absorvendo e emitindo radiação, e, mesmo no vácuo, há criação e aniquilação de partículas a todo momento. Em 2004, o CERN (Conselho Europeu para Pesquisas Nucleares) inaugurou uma estátua de Shiva no interior da instituição (Fig. 2), mencionando o trabalho de Capra.
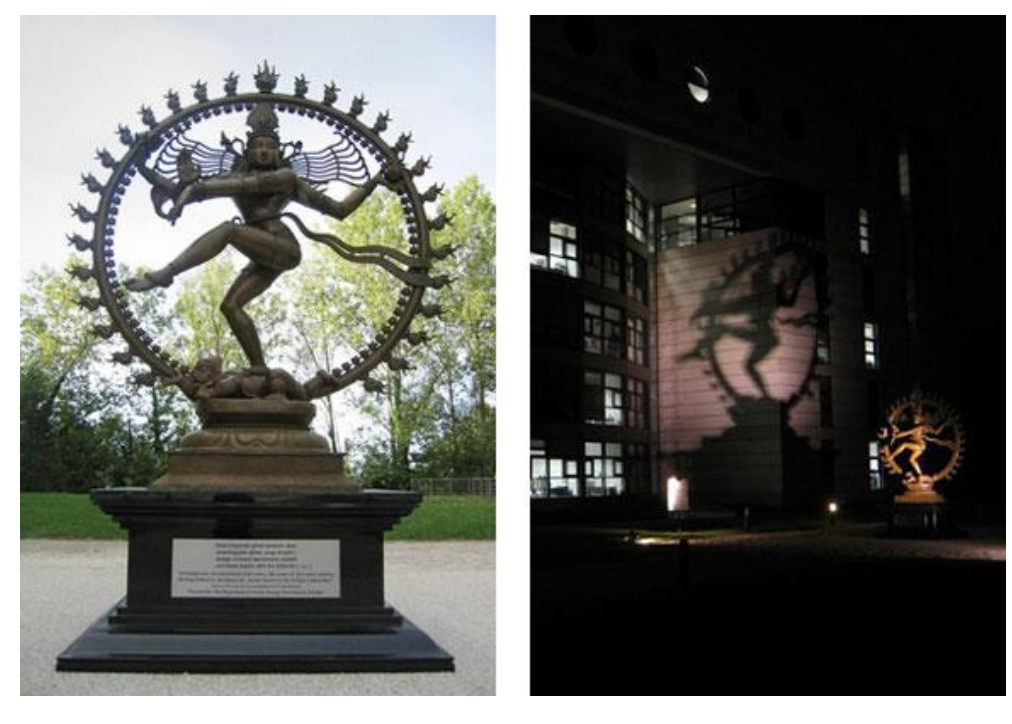

Fig. 2 - Estátua de Shiva no CERN, mencionando a metáfora de Capra. Imagem retirada de <http://www.fritjofcapra.net/shivas-cosmic-dance-at-cern/>.

De acordo com o site de Capra (2004), a placa traz as seguintes menções:

Mais recentemente, Fritjof Capra explicou que "A Física Moderna mostrou que a criação e a destruição não se manifestam somente nas estações do ano e no nascimento e na morte das criaturas vistas, mas é a essência básica da matéria inorgânica" e que "para o Físico moderno, a dança de Shiva é a dança da matéria subatômica." (...) É realmente como Capra conclui: "Centenas de anos atrás, artistas indianos criaram imagens visuais de Shiva dançando em belas séries de bronze. No nosso tempo, os físicos usaram as tecnologias mais avançadas para retratar a dan- 
ça cósmica. A metáfora da dança cósmica, portanto, unifica mitologia antiga, religião e fisica moderna".

Em especial, Capra alinha seu pensamento a uma perspectiva ontológica desenvolvida no contexto da Física Quântica - a filosofia bootstrap, a qual se opõe radicalmente à tradicional Física de partículas, pois considera que a natureza não pode ser reduzida a entidades fundamentais, como as partículas elementares e os campos fundamentais. Em contrapartida, a natureza é entendida a partir da sua própria autoconsistência, sendo os seus componentes consistentes entre si e consigo mesmo (CHEW, 1968). Essa visão de mundo proposta por Geoffrey Chew é chamada de filosofia bootstrap e deriva da teoria da Matriz-S iniciada por Heisenberg na década de 1940 (ROCHA, 2017). A ideia central da Matriz-S é a de que todas as propriedades dos hádrons podem ser determinadas sem a necessidade de introduzir parâmetros empíricos arbitrários, como as partículas elementares (quarks). Em artigo publicado na década de 1940, Heisenberg (1943) mostrou que a Matriz-S é capaz de fornecer, a partir de quantidades observáveis do estado inicial - como as "seções de espalhamentos", os "tempos de vida médios" e as "energias de ligação" -, quantidades observáveis do estado final, sem a necessidade de postular a existência de objetos inobserváveis como as partículas elementares.

Essa nova concepção de autoconsistência dos sistemas hadrônicos, ou seja, a possibilidade de determinar probabilidades de hádrons sem a inserção de parâmetros empíricos arbitrários e com a priorização de um entendimento global dos fenômenos, pode levar a uma interpretação holística da natureza (ROCHA, 2017). Capra percebeu que a filosofia bootstrap leva, de fato, a uma nova visão de mundo. Para o autor, a filosofia bootstrap é a que mais se aproxima do pensamento oriental, não só pela sua filosofia em si, mas também pela sua concepção de matéria. Para Capra, a filosofia bootstrap constitui a rejeição final dos ideais mecanicistas pela nova visão de mundo da Física Moderna. Geoffrey Chew com sua filosofia, na visão de Capra, dá o terceiro passo revolucionário na Física do século XX, depois de Einstein e a relatividade; e Bohr e Heisenberg com sua interpretação da Mecânica Quântica (CAPRA, 2011).

Sintetizando, a moldura filosófica do novo paradigma pode ser descrita em seis aspectos (CAPRA, 2011): 1) não reducionista; 2) foco em processos e não estruturas; 3) é uma ciência epistêmica (ciência que leva em conta o papel do cientista, da teoria e dos instrumentos nos resultados obtidos) e não objetiva; 4) é uma ciência em rede, sem bases fundacionais; 5) não busca verdades, mas descrições aproximadas e 6) adota um comportamento cooperativo e de não-violência ao invés do ideal de exploração da ciência tradicional.

\section{IV.1 Implicações da Filosofia da Física Moderna para outras áreas da Cultura}

Assim como a filosofia da Física Clássica impactou o desenvolvimento de diversas ciências e áreas da cultura, Capra apresenta estudos e pesquisas que são desenvolvidos em consonância com a moldura filosófica da Física Moderna. Isso não significa, entretanto, de- 
fender uma visão de mundo idealista, espiritualista ou subjetivista. O ponto principal da moldura filosófica se dá em sua perspectiva não-reducionista, ecológica (sistêmica) e, portanto, relacional. Essa visão é, então, apresentada para repensar o conceito de vida, saúde e cura, psicologia e economia (CAPRA, 2012a).

No livro A Teia da Vida, Capra (2012b) discute uma noção sistêmica de vida. Em oposição à visão cartesiana, um organismo vivo não pode ser entendido como um relógio, mas como um sistema complexo e aberto que depende da relação interna de seus componentes e da relação com o ambiente. Nesse livro, Capra apresenta a contribuição de diferentes pesquisadores, principalmente da área de sistemas termodinâmicos complexos e não lineares, para discutir a vida como um fenômeno também físico. Essa visão relacional da vida pode ser encontrada em diversos autores e, hoje, discute-se o fato de que, ao invés de pensarmos apenas que uma espécie reúne diferentes indivíduos, um indivíduo é um conjunto de várias espécies (LIDGARD; NYHART, 2017). Isto é, no caso do ser humano, por exemplo, precisamos levar em conta todo conjunto de microrganismos que funcionam no corpo e impactam diretamente na saúde do organismo. Assim, o indivíduo vivo nunca pode ser estabelecido isoladamente, mas em relações ecológicas.

Assim, a visão de tratamento e de saúde não pode ser entendido como o problema de consertar uma peça isolada em um relógio. Capra ressalta que a definição de saúde da OMS já leva em conta esses aspectos quando define saúde como "um estado de completo bem-estar físico, mental e social e não somente ausência de afecções e enfermidades", ou seja, diferentemente do modelo biomédico cartesiano, a nova moldura filosófica enseja a busca por práticas e terapias que promovam bem-estar psíquico e social. Isso significa reconhecer que a saúde também ocorre "fora da pele": uma sociedade saudável é necessária para que haja indivíduos saudáveis - reforçando a visão ecológica de saúde. Com isso em mente, Capra reconhece que terapias desenvolvidas fora do âmbito científico, como Terapias Integrativas, podem servir ao desenvolvimento da saúde dentro de uma concepção holística. No Brasil, o desenvolvimento de Terapias Integrativas tem sido uma das tônicas das políticas públicas de saúde recentes, o que tem causado controvérsia na comunidade científica (LIMA; NASCIMENTO, 2018).

Em especial, para entender a saúde mental é necessário, também, romper com a psicologia cartesiana e entender os aspectos ecológicos da mente (CAPRA, 2012a). Nesse sentido, Capra ressalta a psicologia junguiana como um exemplo de visão sistêmica da mente (BATESON, 2000). Em especial, os conceitos de sincronicidade e de forças psíquicas de Jung teriam alguma influência ou diálogo com a filosofia da Física Moderna.

Por fim, a concepção filosófica ecológica se opõe à ruptura entre natureza e sujeito e deixa de entender a realidade como algo inerte pronto para ser explorado. Por isso, para Capra, um mundo ecológico é necessariamente um mundo não capitalista, uma vez que o capitalismo se desenvolve a partir da possibilidade de exploração da natureza. Para Capra, o capitalismo, o machismo e o racismo são diferentes manifestações da mesma concepção de mundo 
patriarcal, que acredita que o homem branco pode explorar tudo ao seu redor. Principalmente a partir de obras como A Teia da Vida (CAPRA, 2012b), a visão de Capra parece se alinhar com tendências neomarxistas e com o feminismo, mais especificamente com o ecofeminismo (MIES; SHIVA, 2014), uma vertente vinculada à ecologia. Esse alinhamento se torna claro em suas argumentações a favor da substituição do modelo de desenvolvimento exploratório por um modelo sustentável (CAPRA, 2002).

\section{Implicações para o Ensino de Física e para a Pesquisa em Ensino de Física}

Nesta seção, apresentaremos hipóteses sobre a forma com que o paradigma tradicional moldou o sistema educacional em geral, e o Educação em Ciências em particular, desde sua estrutura até suas metodologias. Também vamos discutir de que maneira as pesquisas na área de ensino, que seguiram a mesma postura filosófica hegemônica, contribuíram para a manutenção dos ideais do paradigma tradicional. Ademais, discutimos de que forma a nova moldura filosófica apresentada por Capra pode contribuir para uma alteração nos processos pedagógicos e de pesquisa na área da Educação em Ciências.

\section{V.1 O Ensino de Física}

O paradigma newtoniano-cartesiano não influenciou apenas a ciência do século XIX e de boa parte do século XX, mas, também, a educação em todos os seus níveis de ensino. Como vimos anteriormente, esta forma de pensamento propõe a fragmentação do todo, que se refletiu, nas escolas, na repartição do conhecimento em áreas, em cursos e em disciplinas. Essa influência não se revela, entretanto, apenas na estrutura organizacional do conhecimento, mas também na própria prática pedagógica. A percepção de que o processo pedagógico pode ser apartado de outras dimensões da sociedade, como política e economia, é herança da visão cartesiana de separação entre natureza e seres humanos. Para Contreras (2002), as práticas docentes pautadas pela lógica cientificista têm como foco apenas a melhoria da eficiência do processo de ensino, incorporando soluções instrumentais desenvolvidas a partir de uma concepção positivista. Dessa forma, ainda que a fragmentação do conhecimento possa trazer possíveis benefícios, como o domínio e acúmulo de conhecimento pela especialização, os problemas da sociedade contemporânea exigem a adoção de uma concepção sistêmica sobre a realidade e a informação.

\section{V.1.1 Visão Mecanicista no Ensino de Física}

Capra (2012a) mostrou que o pensamento mecanicista impactou historicamente diferentes áreas do conhecimento como a biologia, a medicina, a economia e a psicologia. Este impacto não foi menor no campo educacional. Na sala de aula pautada por este paradigma hegemônico, o professor é o detentor do saber, aquele que assume uma posição de superioridade em relação aos alunos. A tarefa docente consiste em transmitir todo o seu conhecimento 
acumulado ao longo dos anos de especialização em determinada área do conhecimento. $\mathrm{O}$ papel dos estudantes, por sua vez, é o de assimilar, memorizar e reproduzir, da melhor maneira possível, aquilo que lhes foi transmitido. Esse cenário é observado tanto em espaços da educação básica como da educação superior. Ao caminhar por corredores de escolas ou de universidades, salvaguardadas algumas exceções, pode-se observar professores explicando os conteúdos pelos quais reservam extremo carinho e devoção e os alunos espectadores copiando tudo aquilo que é transmitido pelo mestre. Nesses termos, o bom professor é aquele que domina o seu conteúdo, é exigente e severo, tendo o silêncio e a disciplina como condições essenciais para o ensino conservador e reprodutivo (BEHRENS, 1999). De certa forma, o paradigma mecanicista subsidia o que Freire (1997) denomina de educação bancária, o que Boaventura (SANTOS; MENESES, 2009) denomina de epistemicídio e Lemke (2011) de [educação] conservadora e machista.

As práticas pedagógicas ainda reproduzem uma sistemática pautada pelos pressupostos que deram origem ao campo educacional. Os processos de aprendizagem são entendidos, nesse sentido, como lineares e bem determinados, como se ensino e aprendizagem pudessem ser separados um do outro. O professor transfere todo o seu conhecimento, que já havia sido criado por cientistas antes dele, e o aluno consegue assimilar tudo inequivocamente. Esta é uma influência direta do determinismo presente no paradigma mecanicista, mais especialmente uma consequência da divisão entre o eu e o mundo proposta por Descartes. Esse modelo de epistemologia docente é denominado por Contreras (2002) como racionalista técnico.

Todo o sucesso da Mecânica newtoniana observado nos séculos XVIII e XIX fez com que seus pressupostos e implicações se cristalizassem nas práticas pedagógicas docentes, tanto na Física, como nas outras áreas. No caso do Ensino de Física, a despeito do surgimento da Física Moderna, que exige uma nova postura filosófica para seu entendimento e compreensão (CAPRA, 1989) e da sua inserção nos bancos escolares na metade final do século XX (OSTERMANN; MOREIRA, 2000), o que se observa em linhas gerais é a manutenção de práticas tradicionais de ensino, como se fosse possível ensinar esta nova Física tendo como base o velho paradigma (JOHANSSON et al., 2018). Quer dizer, por mais que os professores de Física estejam trabalhando conceitos contemporâneos de Física, não conseguem se despir dos hábitos clássicos de pensamento e de ação (MERMIN, 1974), fato semelhante ao ocorrido com a maioria dos físicos em atuação (CAPRA, 1989).

Como discutido previamente, apesar de reconhecermos que o paradigma mecanicista tenha subsidiado o surgimento de diversas áreas da cultura, ele não pode mais ser utilizado para a interpretação das questões complexas que envolvem a sociedade contemporânea como apontado pelos pensadores do movimento CTS (AULER, 2018) - afinal, saber calcular a força sobre um bloco em um plano inclinado com atrito pouco ajuda a decidir sobre questões como o aquecimento global, distribuição de energia, futuro da previdência, entre tantas outras questões que interessam. Esta nova linha de ação deve se estender às práticas pedagógicas dos professores em geral e dos professores de Física em particular (MOURA, 2019; 
NASCIMENTO et al., 2019). Na próxima seção, apresentamos uma reflexão sobre de que maneira a visão ecológica de Capra pode contribuir com essa discussão.

\title{
V.1.2 Visão Ecológica no Ensino de Física
}

As mudanças substanciais da virada do século XX e, em especial, do paradigma da ciência podem conduzir ao repensar do sistema educacional e das práticas pedagógicas desenvolvidas nas escolas e nas universidades. Capra nos indica que estamos passando por uma crise profunda na sociedade, uma crise complexa e multidimensional, a qual afeta diversos aspectos da nossa vida (CAPRA, 2012a). Para enfrentar essa complexidade, o autor nos apresenta uma visão de mundo baseada na interdependência e na busca de uma dimensão de totalidade. Nas palavras do autor:

\begin{abstract}
Em contraste com a concepção mecanicista cartesiana, a visão de mundo que está surgindo a partir da física moderna pode caracterizar-se por palavras como orgânica, holística e ecológica. Pode ser também denominada visão sistêmica, no sentido da teoria geral dos sistemas. O universo deixa de ser visto como uma máquina, composta de uma infinidade de objetos, para ser descrito como um todo dinâmico, indivisivel, cujas partes estão essencialmente inter-relacionadas e só podem ser entendidas como modelos de um processo cósmico (CAPRA, 2012a, p. 72).
\end{abstract}

Entende-se que essa visão de mundo pode contribuir com a reformulação da estrutura organizacional do ensino e também com as práticas pedagógicas dos professores (BEHRENS, 2005; MORAES, 2007). Capra não trata especialmente do campo educacional nas suas obras, contudo, a partir do entendimento de que a visão de mundo apresentada serve de background para todas as áreas, a reflexão sobre uma nova perspectiva de ensino pode ser muito bem desenvolvida. Sobre a mudança de paradigma na educação, Moraes destaca que:

\begin{abstract}
A ciência está exigindo uma nova visão de mundo, diferente e não fragmentada. A atual abordagem que analisa o mundo em partes independentes já não funciona. Por outro lado acreditamos na necessidade de construção e reconstrução do homem e do mundo, tendo como um dos eixos fundamentais, a educação, reconhecendo a importância de diálogos que precisam ser restabelecidos, com base em um enfoque mais holístico e em um modo menos fragmentado de ver um mundo e nos posicionarmos diante dele. Já não podemos prescindir de uma visão mais ampla, global para que a mente humana funcione de modo mais harmonioso no sentido de colaborar para a construção de uma sociedade mais ordenada, justa, humana, fraterna e estável (MORAES, 2007, p. 20).
\end{abstract}

Em contraponto à fragmentação das disciplinas e áreas do conhecimento dentro da escola, produto do paradigma mecanicista, é necessário investir na interdisciplinaridade para dar conta da complexidade dos problemas modernos. É importante destacar que não estamos nos referindo à interdisciplinaridade como uma simples junção de disciplinas, o que resultaria 
apenas em uma reestruturação curricular, mas sim em uma nova postura frente ao conhecimento (FAZENDA, 2008). A iniciativa de simplesmente unir disciplinas específicas em áreas do conhecimento sem a real integração entre elas, como proposto nos Parâmetros Curriculares Nacionais para o Ensino Médio, se revelou inócua (ABREU, 2002). Quer dizer, não é suficiente unir disciplinas em áreas se elas mantiverem todas as suas características, limites, processos, filosofias e estrutura iniciais.

A integração disciplinar que estamos propondo neste trabalho como alternativa à fragmentação, produto do paradigma mecanicista, muito inspirada por Capra (2012a), precisa levar em consideração o fato das disciplinas serem estruturas construídas de modo social e histórico a partir de relações de poder e de interesses sociais. Nas palavras de Abreu (2002), as disciplinas são "espaços de luta e conflitos com fronteiras estabelecidas e construídas dentro deste contexto. Refletem posições de prestígio e status que determinam a organização do conhecimento escolar".

Nesses termos, a redução das fronteiras de disciplinas tradicionais como a Física para associá-la a outros campos do conhecimento com o objetivo de promover um entendimento mais profundo dos problemas complexos, que cada vez mais se apresentam, esbarra em relações de poder, pois conflita diretamente com o status que esse corpo de conhecimento adquiriu ao longo dos séculos. O próprio Capra (2012a) reconhece que sua aproximação da Física ao misticismo oriental foi considerada pelos físicos como "altamente não-científica".

Dessa forma, reconhecemos que um novo paradigma para a educação, baseado na visão ecológica de Capra, não será facilmente interpenetrado nos ambientes escolares, por dois motivos principais. O primeiro tem relação com a formação dos profissionais da educação em geral e muito especialmente dos professores de Física. A licenciatura em Física no Brasil - e possivelmente outras licenciaturas também - estão muitas vezes organizadas de forma que claramente se identificam as disciplinas específicas e as pedagógicas no currículo, muito bem separadas umas das outras, por motivos historicamente estabelecidos, a dizer, o desenvolvimento da legislação que rege a organização da licenciatura em Física no Brasil (ARAUJO; VIANNA, 2010).

Assim, os professores que lecionam nas escolas e nas universidades foram ensinados neste formato de separação entre as áreas, reflexo do paradigma newtoniano-cartesiano. Não podemos esperar que os docentes cheguem nas escolas depois de vivenciarem tal formação e que desenvolvam uma prática associada com uma visão sistêmica e holística do mundo. Assim, é preciso repensar primeiramente o currículo dos cursos de formação inicial de professores e, também, investir em cursos de aperfeiçoamento para docentes em formação.

O segundo motivo, já mencionado anteriormente, tem um cunho político e se associa com as relações de poder que forjam historicamente o desenvolvimento das disciplinas escolares. Os profissionais das áreas específicas necessariamente teriam que abrir mão da especificidade da sua disciplina em favor de uma visão mais ecológica, algo que necessariamente demandaria uma disputa política. Ademais, todos os materiais didáticos produzidos estão 
formatados no paradigma mecanicista, com as disciplinas muito bem caracterizadas e delimitadas. Sabe-se que os professores adotam livros didáticos extremamente tradicionais e conservadores mesmo nos capítulos sobre Física Moderna (LIMA; OSTERMANN; CAVALCANTI, 2017). Dessa maneira, todas as editoras que se beneficiam da venda desses materiais não investiriam em novas abordagens sabendo da preferência dos profissionais da educação. Nota-se aqui uma relação próxima entre os dois motivos apresentados. A formação dos professores no paradigma mecanicista parece, em princípio, ser um dos principais entraves para a consolidação do paradigma ecológico dentro das escolas. Outros fatores relacionados podem ser a própria forma de seleção para ingresso no ensino superior, a Base Nacional Comum Curricular, e a própria percepção da sociedade sobre o papel da escola. O surgimento de movimentos como Escola Sem Partido revela que muitos setores da sociedade acreditam que a função do professor é ensinar os conteúdos "neutros e objetivos" da ciência. Em contrapartida, há estudos que mostram que os alunos com maior interesse em política também são os que apresentam melhor desempenho no ENEM em provas de Ciências da Natureza (NASCIMENTO et al., 2019). Entendendo que os professores não devem ser culpabilizados neste processo (CAVALCANTI; NASCIMENTO; OSTERMANN, 2018), reforçamos a necessidade de um novo enfoque dos cursos de formação inicial e continuada a fim de iniciar um movimento de mudança paradigmática no Ensino de Física.

Por fim, mais um sintoma dessa visão linear e fragmentada é a já bem conhecida separação entre a Universidade e a Educação Básica. Sabe-se que, em geral, as pesquisas realizadas na área de Ensino demoram a chegar nas escolas ou a refletirem em documentos oficiais e livros didáticos, apesar dos esforços atuais de eliminação de brechas desse tipo. A estrutura hierarquizada das relações de poder estabelecida entre os "especialistas da educação" e os professores reforça o mito da superioridade dos especialistas (AULER, 2018) e viabiliza a produção de uma série de pesquisas em Ensino totalmente alheias à realidade escolar brasileira.

\section{V.2 A Pesquisa em Ensino de Física}

A pesquisa em Ensino de Física ainda em sua grande parte é alinhada com o paradigma hegemônico da ciência tradicional. De uma forma geral, as pesquisas da área buscam diferentes formas para se ensinar mais e melhor a Física verdadeira e absoluta a qual, não por coincidência, foi desenvolvida em grande parte por homens brancos (LEMKE, 2011). Mesmo alguns dos trabalhos que buscam discutir NdC ou CTS acabam por reforçar a ciência branca masculina como o centro de sua temática. Nesse sentido, ensina-se Física para melhor entender e dominar a natureza, veiculando a antiga visão de dominação e exploração. Além disso, os métodos de pesquisa tradicionais, de uma forma geral, buscam na receita cartesiana a garantia de sua confiabilidade. A pesquisa em Ensino de Física tradicional trouxe grandes contribuições para o campo educacional, assim como a filosofia cartesiana trouxe grandes contribuições para a sociedade moderna. Isso não significa, entretanto, que ela seja capaz de dar 
conta dos problemas da contemporaneidade. Pelo contrário, conforme argumenta Capra, é justamente a inadequação do paradigma hegemônico que enseja a necessidade de uma nova moldura filosófica capaz de lidar com nossos problemas atuais.

Desenvolver uma pesquisa em ensino no paradigma ecológico, por outro lado, significa, do ponto de vista temático, ter que abandonar o ensino "de Física" como objeto, pois as relações ecológicas exigem a superação das barreiras disciplinares. Ademais, em termos epistemológicos, a pesquisa no paradigma ecológico pode reconhecer e legitimar as produções de conhecimento que se dão em esferas não tradicionalmente rotuladas como científicas. Em termos de problemas de pesquisa, deve-se olhar para problemas concretos, que traduzam a nossa existência extremamente complexa, sem buscar reducionismos simplistas. Ou seja, devemos aceitar que os problemas educacionais não podem ser resolvidos apenas na esfera cognitiva ou apenas na esfera social, mas que envolvem, ao mesmo tempo, questões cognitivas, discursivas, afetivas e sociais. Por fim, em termos de metodologia, as pesquisas no paradigma ecológico devem preconizar a análise de processos e não de produtos. Com isso, é preciso investir na reformulação das metodologias de pesquisa do Ensino de Física, dialogando com referenciais de outras áreas do conhecimento a fim de melhor enfrentar os problemas complexos que atualmente se apresentam no campo educacional.

\section{Considerações finais}

Neste trabalho, foi apresentado o pensamento sistêmico de Fritjof Capra com foco em suas ideias sobre o paradigma ecológico que possibilita analisar a relação entre sujeito, ambiente e sociedade utilizando como referência seus pressupostos estabelecidos em $\mathrm{O}$ Tao da Física (CAPRA, 1989), A Teia da Vida (CAPRA, 2012b) e O Ponto de Mutação (CAPRA, 2012a). Esse novo paradigma surge em contraponto a um paradigma baseado em premissas da Física Clássica que enfocamos nas seções 2 e 3 desse artigo para demonstrar que Capra não traz uma ruptura radical em sua descrição de ciência à qual ele mesmo ainda atribui características metodológicas bem específicas, apesar de reconhecer aspectos subjetivos no desenvolvimento do conhecimento científico (CAPRA, 1989). Entretanto, ao descrever sua visão ecológica, o autor argumenta a favor de uma moldura filosófica verdadeiramente interdisciplinar, sem bases fundacionais, e capaz de fomentar diálogos intelectualmente honestos entre ciência, espiritualidade e aspectos místicos de filosofias orientais. Nessa moldura, a ciência se configura de maneira não-reducionista, processual, epistêmica, não objetiva e cooperativa.

Como algumas das articulações resultantes da concepção de um novo paradigma, destacamos esforços como os estudos sobre organismos vivos, tradicionalmente construídos pelas áreas da Saúde, enfocados sob o olhar da Física e analisados como sistemicamente complexos e abertos (CAPRA, 2012b). Nesse sentido, destacamos também as ciências econômicas e seu desenvolvimento, inspirado no paradigma mecanicista e autodeclarado livre de valores e crenças subjetivas, que poderia se desdobrar, a partir da visão em rede de Capra, em uma melhor construção de conhecimentos se considerasse preceitos ecológicos e relacionais 
(CAPRA, 2012a). As práticas relacionadas à saúde mental também poderiam ter preceitos revisitados, se não mais se embasassem em uma psicologia cartesiana, para, por fim, desenvolver uma visão sistêmica mais próxima da psicologia junguiana, como ressalta Capra.

Como exemplo dos diálogos entre ciência e espiritualidade, destacamos os paralelos entre Física Quântica e o misticismo oriental construídos em O Tao da Física (CAPRA, 1989): o reconhecimento de que todos os fenômenos são manifestações de uma realidade fundamentalmente una, a noção de complementaridade entre os opostos, a visão de um universo composto primordialmente pelo vazio e não só pelo que experienciamos como tangível e, por último, o caráter dinâmico e mutável da realidade. Sobre tais paralelos, concentramo-nos em demonstrar que não foram construídos com o objeto de igualar os construtos místicos orientais às conclusões científicas modernas, mas para apontar compatibilidades e pontos de convergência na cosmovisão das filosofias budistas, taoístas e hinduístas e as descobertas da Física Moderna.

Destacamos que a obra de Capra identifica o novo paradigma como o caminho viável para se enfrentar as questões que se apresentam atualmente à sociedade de modo que, tornando turvas as barreiras entre as áreas de conhecimento, sermos capazes de melhor administrar nossa compreensão sobre os fenômenos contemporâneos ao construir propostas de solução. Sendo necessário que as áreas de Educação em Ciências e Ensino de Física lidem com esses problemas da atualidade de maneira eficiente, argumentamos que, apesar de não possuir análises direcionadas à educação e sistemas de ensino, as ideias de Capra são capazes de contribuir com a remodelação do ensino, favorecendo currículos colaborativos, não-fragmentados, e práticas pedagógicas com preceitos ecológicos.

Por fim, recobramos a defesa do potencial de Fritjof Capra como epistemólogo, e de sua Filosofia Sistêmica como referencial teórico, reconhecendo-o como autor de ideias dignas de serem exploradas na área de Ensino, como argumentamos na seção 5 do presente artigo, e em reflexões sobre a Natureza da Ciência de um modo geral. A construção teórica de seu trabalho desde a década de 1970, que no presente artigo chamamos de Filosofia Sistêmica, ao buscar a integração das dimensões biológicas, ecológicas, sociais e cognitivas da vida e ao buscar a concatenação de mudanças conceituais na ciência com mudanças mais amplas em valores e visões de mundo presentes na sociedade (CAPRA, 2014), pode representar um novo embasamento para trabalhos que buscam abordar temas como a educação ecológica.

\section{Referências}

ABD-EL-KHALICK, F.; LEDERMAN, N. G. Improving science teachers' conceptions of nature of science: A critical review of the literature. International Journal of Science Education, v. 22, n. 7, p. 665-701, 2000.

ABREU, R. A integração curricular na área das ciências da natureza, matemática e suas tecnologias nos parâmetros curriculares nacionais para o ensino médio. 2002. 
Dissertação (Mestrado em Educação) - UFRJ, Rio de Janeiro.

AIKENHEAD, G. Review of Research on Humanistic Perspectives in Science Curricula. In: EUROPEAN SCIENCE EDUCATION RESEARCH ASSOCIATION (ESERA) 2003 CONFERENCE, Atas... Noordwijkerhout: 2003. Disponível em: <https://www.usask.ca/education/profiles/aikenhead/webpage/ESERA_2.pdf>.

AMÉRICO, P. A Ciência e os Sistemas: Questões de História e Filosofia Natural. 4. ed. João Pessoa: Editora Universitária, 2001.

ARAUJO, R. S.; VIANNA, D. M. A história da legislação dos cursos de Licenciatura em Física no Brasil: do colonial presencial ao digital a distância. Revista Brasileira de Ensino de Física, v. 32, n. 4, p. 4403-1-4403-11, 2010. Disponível em: <http://www.scielo.br/scielo.php?script=sci_arttext\&pid=S1806-11172010000400010\&lng $=\mathrm{pt} \& \operatorname{tlng}=\mathrm{pt}>$.

ARENDT, H. A Condição Humana. Tradução: Roberto Raposo. 13. ed. Rio de Janeiro: Forense Universitária, 2007. 474 p.

AULER, D. Cuidado! Um Cavalo Viciado Tende a Voltar para o Mesmo Lugar. Curitiba: Appris Editora, 2018. 151 p.

BACHELARD, G. A Filosofia do Não: Filosofia do novo espírito científico. Tradução: Joaquim José Moura Ramos. Editorial Presença, 2009. 136 p.

BACON, F. Novum organum ou verdadeiras indicações acerca da interpretação da natureza: Nova Atlântida. Tradução: J. A. R. Andrade. Abril Cultural, 1984. 272 p.

BAGDONAS, A.; SILVA, C. C. Enhancing Teachers' Awareness About Relations Between Science and Religion. Science \& Education, v. 24, n. 9, p. 1173-1199, 2015.

BARBOUR, I. G. Religion in an age of science: The Gifford Lectures 1989-1991. San Francisco: Harper Collins, 1990. 297 p. v. 1.

BATESON, G. Steps to an ecology of mind: Collected essays in anthropology, psychiatry, evolution, and epistemology. Chicago: University of Chicago Press, 2000. 533 p.

BEHRENS, M. A. A Prática Pedagógica e o Desafio do Paradigma Emergente. Revista Brasileira de Estudos Pedagógicos, v. 80, p. 383-303, 1999.

BEHREnS, M. A. O Paradigma Emergente e a Prática Pedagógica. Petrópolis: Vozes, 2005.

BUNGE, M. Materia y mente: Una investigación filosófica. Ciudad de México: SIGLO XXI MEXICO, 2016. 528 p. 
CAPRA, F. O Tao da Física: Uma exploração dos paralelos entre a física moderna e o misticismo oriental. Tradução: Maria José Quelhas Dias \& José Carlos Almeida. Editorial Presença, 1989.

CAPRA, F. As Conexões Ocultas: Ciência para uma vida sustentável. Tradução: Marcelo Brandão Cipolla. 1. ed. São Paulo: Cultrix, 2002. 296 p.

CAPRA, F. Shiva's Cosmic Dance at CERN. Fritjof Capra, 2004. Disponível em: <https://www.fritjofcapra.net/shivas-cosmic-dance-at-cern/>. Acesso em: 9 set. 2019.

CAPRA, F. O Tao da Física: Uma análise dos paralelos entre a física moderna e o misticismo oriental. Tradução: José Fernandes Dias. 28. ed. São Paulo: Cultrix, 2011. 376 p.

CAPRA, F. O Ponto de Mutação: A ciência, a sociedade e a cultura emergente. Tradução: Álvaro Cabral. 25. ed. São Paulo: Cultrix, 2012. 432 p. a.

CAPRA, F. A Teia da Vida: Uma nova compreensão científica dos sistemas vivos. Tradução: Newton Roberval Eichemberg. 1. ed. São Paulo: Cultrix, 2012. b.

CAPRA, F. About Fritjof Capra, 2014. Disponível em:

<https://www.fritjofcapra.net/about/>. Acesso em: 9 set. 2019.

CAVALCANTI, C.; NASCIMENTO, M.; OSTERMANN, F. A falácia da culpabilização do professor pelo fracasso escolar. Revista Thema, v. 15, n. 3, p. 1064-1088, 2018. Disponível em: <http://revistathema.ifsul.edu.br/index.php/thema/article/view/1059>.

CHEW, G. F. “Bootstrap”: A scientific idea? Science, v. 161, n. 3843, p. 762-765, 1968.

CONTRERAS, J. A autonomia de professores. Tradução: Sandra Trabucco Valenzuela. São Paulo: Cortez, 2002. 296 p.

DASTON, L.; GALISON, P. Objectivity. New York: Zone Books, 2007.

DELIZOICOV, D. et al. Sociogenese do conhecimento e Pesquis em Ensino: Contribuições a partir do Referencial do Fleckiano. Caderno Brasileiro de Ensino de Física, v. 19, n. especial, p. 52-69, 2002.

DESCARTES, R. Discurso do Método. Tradução: Maria Ermantina Galvão. 3. ed. São Paulo: Martins Fontes, 2001.

EINSTEIN, A. Über einen die Erzeugung und Verwandlung des Lichtes betreffenden heuristischen Gesichtspunkt. Annalen der Physik, v. 322, n. 6, p. 132-148, 1905. a. Disponível em: <http://doi.wiley.com/10.1002/andp.19053220607〉.

EINSTEIN, A. Zur Elektrodynamik bewegter Körper. Annalen der Physik, v. 322, n. 10, p. 891-921, 1905. b. Disponível em: <http://doi.wiley.com/10.1002/andp.19053221004>. 
EINSTEIN, A. Física e realidade. Revista Brasileira de Ensino de Física, v. 28, n. 1, p. 922, 2006. Disponível em: <http://www.scielo.br/scielo.php?script=sci_arttext\&pid=S1806$11172006000100003 \& \operatorname{lng}=\mathrm{pt} \& \operatorname{lng}=\mathrm{pt}>$.

FAZENDA, I. C. A. Interdisciplinaridade e transdisciplinaridade na formação de professores. Ideação, v. 10, n. 1, p. 93-104, 2008.

FEYERABEND, P. Against the Method. 4. ed. London: Verso, 2010. 336 p.

FEYERABEND, P. Adeus à razão. Tradução: Vera Joscelyne. 1. ed. São Paulo: Editora UNESP, 2010. 400 p.

FEYERABEND, P. A Ciência em uma sociedade livre. Tradução: Vera Joscelyne. 1. ed. São Paulo: Editora UNESP, 2011. 288 p.

FOSTER, J. B. The Anthropocene Crisis. Monthly Review, v. 68, n. 4, p. 9, 2016. In: HAMILTON, C.; GEMENNE, F.; BONNEUIL, C. (Eds.). The Anthropocene and the global environmental crisis: Rethinking modernity in a new epoch. London: Routledge, 2015.

FOUCAULT, M. Microfísica do Poder. Tradução: Roberto Machado. 28. ed. Rio de Janeiro: Paz e Terra, 2018.

FREIRE JR, O.; PESSOA JR, O.; BROMBERG, J. L. Teoria quântica - estudos históricos e implicações culturais. Campina Grande: EDUEPB, São Paulo: Livraria da Física, 2011. 456 p.

FREIRE, P. Educação "bancária" e educação libertadora. Introdução à psicologia escolar, v. 3, p. 61-78, 1997.

FREIRE, P. Pedagogia da Autonomia: saberes necessários à prática educativa. Rio de Janeiro: Paz e Terra, 2013.

GALILEI, G. Dialogues Concerning Two New Sciences by Galileo Galilei. Tradução: Henry Crew \& Alfonso de Salvio. New York: Macmillan, 1914. 336 p.

GOSWAMI, A. Consciousness in quantum physics and the mind-body problem. Journal of Mind and Behavior, US, v. 11, n. 1, p. 75-96, 1990.

GOSWAMI, A. O Médico Quântico: Orientações de um Físico para a Saúde e a Cura. Tradução: Euclides Luiz Calloni \& Cleusa Margô Wosgrau. 1. ed. São Paulo: Cultrix, 2006. $288 \mathrm{p}$.

HARRISON, D. Teaching the Tao of Physics. American Journal of Physics, v. 47, n. 9, p. 779-783, 1979.

HEISENBERG, W. Die "beobachtbaren Größen" in der Theorie der Elementarteilchen. 
Zeitschrift für Physik, v. 120, n. 7-10, p. 513-538, 1943. Disponível em: <http://link.springer.com/10.1007/BF01329800>.

HEISENBERG, W. Physics and Beyond: Encounters and Conversations. Tradução: Arnold J. Pomerans. 1. ed. New York: Harper \& Row, 1972. 267 p.

JAMMER, M. Einstein e a Religião: Física e Teologia. Tradução: Vera Ribeiro. Rio de Janeiro: Contraponto, 2000. 224 p.

JOHANSSON, A. et al. "Shut up and calculate": the available discursive positions in quantum physics courses. Cultural Studies of Science Education, v. 13, n. 1, p. 205-226, 2018.

KINCHELOE, J. L.; TOBIN, K. The much exaggerated death of positivism. Cultural Studies of Science Education, v. 4, n. 3, p. 513-528, 2009.

KRAGH, H. Matter and Spirit in the Universe: Scientific and Religious Preludes to Modern Cosmology. London: Imperial College Press, 2004. 312 p.

KUHN, T. The Structure of Scientific Revolutions. 3. ed. Chicago: University of Chicago Press, 1996.

LATOUR, B. Pandora's Hope: Essays on the reality of Science Studies. Cambridge: Harvard University Press, 1999. 226 p.

LATOUR, B. Jamais Fomos Modernos. Tradução: Carlos Irineu da Costa. 3. ed. São Paulo: Editora 34, 2013. 152 p.

LEMKE, J. The secret identity of science education: masculine and politically conservative? Cultural Studies of Science Education, v. 6, n. 2, p. 287-292, 2011. Disponível em: <http://link.springer.com/10.1007/s11422-011-9326-6>.

LIDGARD, S.; NYHART, L. K. Biological individuality: Integrating scientific, philosophical, and historical perspectives. Chicago: University of Chicago Press, 2017. 400 p.

LIMA, N. W. et al. A História do Fóton em Livros de Física. Enseñanza de las Ciencias, v. v. extra, p. 1953-1957, 2017.

LIMA, N. W. et al. Um Estudo Metalinguístico sobre as Interpretações do Fóton nos Livros Didáticos de Física Aprovados no PNLDEM 2015: Elementos para uma Sociologia Simétrica da Educação em Ciências. Revista Brasileira de Pesquisa em Educação em Ciências, v. 1, n. 2, p. 331-364, 2018. Disponível em:<https://seer.ufmg.br/index.php/rbpec/article/view/ 9681>.

LIMA, N. W. et al. The Polysemic Nature of Photons: Hybridization and Backwards Causation in Contemporary Undergraduate Quantum Physics Textbooks. In: 
INTERNATIONAL HISTORY, PHILOSOPHY AND SCIENCE TEACHING CONFERENCE, 15, 2019, Thessaloniki. Atas... Thessaloniki: 2019.

LIMA, N. W.; NASCIMENTO, M. M. Terapias Integrativas: Uma Disputa Epistemológica e Política. In: ENCONTRO DE PESQUISA EM ENSINO DE FÍSICA, XVII, 2018, Campos do Jordão. Atas... Campos do Jordão: SBF, 2018.

LIMA, N. W.; OSTERMANN, F.; CAVALCANTI, C. J. de H. A não-modernidade de Bruno Latour e suas implicações para a Educação em Ciências. Caderno Brasileiro de Ensino de Física, v. 35, n. 2, p. 367-388, 2018.

LIMA, N. W.; OSTERMANN, F.; CAVALCANTI, C. J. H. Física Quântica no ensino médio: uma análise bakhtiniana de enunciados em livros didáticos de Física aprovados no PNLDEM2015. Caderno Brasileiro de Ensino de Física, v. 34, n. 2, p. 435, 2017. Disponível em: <https://periodicos.ufsc.br/index.php/fisica/article/view/2175-7941.2017v34 $\mathrm{n} 2 \mathrm{p} 435>$.

LOPES, A. R. C. Bachelard: o filósofo da desilusão. Caderno Catarinense de Ensino de Física, v. 13, n. 3, p. 248-273, 1996. Disponível em: <http://www.joinville.udesc.br/portal/ professores/susana/materiais/Bachelard.pdf>.

MATTHEWS, M. R. A role for history and philosophy in science teaching. Educational Philosophy and Theory, v. 20, n. 2, p. 67-81, 1988.

MELO, T. B.; ALBUQUERQUE, M. B. De; CHRISPINO, A. ENSINO CTS NO BRASIL E CTS NA IBERO-AMÉRICA : IDENTIFICAÇÃO DE ÁREAS DE INTERESSE POR MEIO DE REDES SOCIAIS. Ensenanza de las Sciencias, v. especial, p. 4727-4732, 2017.

MERMIN, N. D. What's Wrong with this Pillow? Physics Today, v. 42, n. 4, p. 9-11, 1974.

MIES, M.; SHIVA, V. Ecofeminism. London: Zed Books, 2014. 360 p.

MORAES, M. C. O Paradigma Educacional Emergente. Campinas: Papirus, 2007. 240 p.

MOURA, C. B. O Ensino de Ciências e a Justiça Social: questões para o debate. Caderno Brasileiro de Ensino de Física, v. 36, n. 1, p. 1-7, 2019. Disponível em: <https://periodicos.ufsc.br/index.php/fisica/article/view/2175-7941.2019v36n1p1>.

MOURA, M. D.; SANTOS, R. P. Detectando misticismo quântico em livros publicados no Brasil com Ciência de Dados. Caderno Brasileiro de Ensino de Física, v. 34, n. 3, p. 725 744, 2017. Disponível em: <https://periodicos.ufsc.br/index.php/fisica/article/view/21757941.2017v34n3p725>.

MUSSATO, G. A. Ontologia e epistemologia na educação científica. 2018. 156 f. Tese (Doutorado em Educação em Ciências e Matemática) - PUCRS, 2018. 
NASCIMENTO, M. M. et al. Cultura política, desempenho escolar e a Educação em Ciências: um estudo empírico à luz de Pierre Bourdieu. Ciência \& Educação (Bauru), v. 25, n. 2, p. 431-447, 2019. Disponível em: <http://www.scielo.br/scielo.php?script=sci_ arttext\&pid=S1516-73132019000200431\&tlng=pt>.

OStermann, F. A epistemologia de Kuhn. Caderno Catarinense de Ensino de Física, v. 13, n. 3, p. 184-96, 1996. Disponível em: <http://www.lume.ufrgs.br/bitstream/handle/ 10183/85016/000257126.pdf?sequence $=1>$.

OSTERMANN, F.; MOREIRA, M. A. Uma revisão bibliográfica sobre a área de pesquisa "Física Moderna e Contemporânea no Ensino Médio". Investigações em ensino de ciências, v. 5, n. 3, p. 23-48, 2000.

PESA, M. A.; OSTERMANN, F. La ciencia como actividad de resolución de problemas: la epistemologia de Larry Laudan y algunos aportes para las investigaciones educativas en ciencias. Caderno Brasileiro de Ensino de Física, v. 19, p. 84-99, 2002. Disponível em: <http://www.lume.ufrgs.br/bitstream/handle/10183/85030/000336312.pdf?sequence=1>.

PESSOA JR., O. Conceitos de Física Quântica. São Paulo: Livraria da Física, 2003. 188 p. v. 1.

PONTES, F.; MELO, T. B. de; CHRISPINO, Á. Temas na pesquisa em ensino CTS brasileiro: um panorama. Indagatio Didactica, v. 8, n. 1, p. 1498-1510, 2016.

POPPER, K. Conjectures and Refutations: The growth of scientific knowledge. London: Routledge, 1963. 412 p.

REGNER, A. C. K. P. Feyerabend e o pluralismo metodológico. Caderno Catarinense de Ensino de Física, v. 13, n. 3, p. 231-247, 1996. Disponível em: <http://nutes2.nutes.ufrj.br/ coordenacao/textosapoio/tap-epis-13.pdf >.

ROCHA, G. R. Uma História Cultural do Reencantamento do Mundo pela Teoria Quântica. 2015. 311 f. Tese (Doutorado em História, Filosofia e Ensino de Ciências) UFBA, 2015.

ROCHA, G. R. Uma História Cultural da Teoria da Matriz-S : Geoffrey Chew e a Filosofia de Bootstrap. Revista Brasileira de História da Ciência, v. 10, n. 1, p. 49-69, 2017.

RUTHERFORD, F. Fostering the History of Science in American Science Education. In: BEVIlACQUA, F.; GIANNETTO, E.; MATTHEWS, M. R. (Eds.). Science Education and Culture: The Contribution of History and Philosophy of Science. Dordrecht: Springer Netherlands, 2001. p. 41-52.

SAITO, M. T. A gênese e o desenvolvimento da relação entre Física Quântica e misticismo e suas contribuições para o Ensino de Ciências. 2018. 354 f. Tese (Doutorado 
em Ciências) - USP, 2018.

SANTOS, B. S. Um discurso sobre as ciências. 5. ed. São Paulo: Cortez, 2008. 92 p.

SANTOS, B. S.; MENESES, M. P. Epistemologias do Sul. São Paulo: Cortez, 2009.

SHAPIN, S.; SCHAFFER, S. Leviathan and the Air-Pump. Princeton: Princeton University Press, 1985.

SILVEIRA, F. L. A filosofia de Karl Popper e suas implicações no ensino da ciência. Caderno Catarinense de Ensino de Física, v. 6, n. 2, p. 148-162, 1989.

SILVEIRA, F. L. A filosofia da ciência de Karl Popper: o racionalismo crítico. Caderno Catarinense de Ensino de Física, v. 5, n. 2, p. 33-42, 2002. Disponível em: <http://www.lume.ufrgs.br/handle/10183/85014>.

SILVEIRA, F. L. A Metodologia dos Programas de Pesquisa: A Epistemologia de Lakatos. Caderno Brasileiro de Ensino de Física, v. 13, n. 3, p. 219-230, 1996.

TEIXEIRA, E. S.; GRECA, I. M.; FREIRE, O. The History and Philosophy of Science in Physics Teaching: A Research Synthesis of Didactic Interventions. Science \& Education, v. 21, n. 6, p. 771-796, 2012.

TOLEDO, C. E. R. et al. Os temas de pesquisa que orbitam o enfoque CTS: uma Análise de Rede sobre as Teses publicadas no Brasil. Desenvolvimento Curricular e Didática, v. 8, n. 1, p. 1367-1383, 2016. 